\title{
CARACTERIZAÇÃO DOS INDIVÍDUOS COM DISTÚRBIOS DA FLUÊNCIA, ATENDIDOS NA CLÍNICA-ESCOLA DO CURSO DE FONOAUDIOLOGIA DA USP-BAURU
}

\author{
Characterization of individuals with fluency disorders at the Speech \\ Language Pathology and Audiology Clinic USP - Bauru
}

Tâmyne Ferreira Duarte ${ }^{(1)}$, Patrícia de Abreu Pinheiro Crenitte ${ }^{(2)}$, Simone Aparecida Lopes-Herrera ${ }^{(3)}$

\begin{abstract}
RESUMO
Objetivo: caracterizar a população de indivíduos atendidos na Clínica de Distúrbios da Fluência do Curso de Fonoaudiologia da USP (Bauru), de 1992 a 2005, quanto à idade, gênero, queixa inicial, diagnóstico fonoaudiológico, antecedentes familiares, manifestações, gravidade e frequência, além de possíveis alterações associadas, comparando tais dados com a literatura estudada. Métodos: análise de 194 prontuários da população acima referida por meio do preenchimento de protocolo com questões referentes às variáveis propostas no objetivo. Resultados: dos 194 prontuários, 140 pertenciam a pacientes do sexo masculino $(72 \%$ da amostra) e $54(28 \%)$, do feminino. Entre as queixas relatadas, $68 \%(n=132)$ eram de gagueira, $23 \%(n=45)$ referiam-se a outros distúrbios da fluência (taquifemia, distúrbio motor da fala) e outras $9 \%(n=17)$ estavam associadas a alterações vocais, linguagem oral e/ou escrita e fala. Quanto a antecedentes familiares, $57 \%(n=110)$ tinham na família mais de um parente com alterações na fala e/ou linguagem. As manifestações das disfluências, citadas em $54 \%$ dos prontuários $(n=105)$ dos indivíduos diagnosticados com gagueira, foram bloqueios, repetições e prolongamentos. Constatou-se histórico de atraso de linguagem nos casos de gagueira em $31 \%$ dos casos $(n=60)$. Conclusão: com base nos dados encontrados, conclui-se que a população estudada caracteriza-se por apresentar: início dos primeiros sintomas entre 1 e 5 anos, maior acometimento no gênero masculino, histórico familiar e de atraso de fala e linguagem positivo, manifestações predominantes de repetição de sílabas, bloqueios, bloqueios acompanhados de prolongamentos e hesitações.
\end{abstract}

DESCRITORES: Comunicação; Gagueira; Linguagem; Sinais e Sintomas

\section{INTRODUÇÃO}

A Fonoaudiologia é uma ciência que tem como objeto de estudo a linguagem e a comunicação

(1) Aluna do Curso de Graduação em Fonoaudiologia da Faculdade de Odontologia de Bauru da Universidade de São Paulo, FOB-USP, Bauru, SP.

(2) Fonoaudióloga; Departamento de Fonoaudiologia da Faculdade de Odontologia de Bauru da Universidade de São Paulo, FOB-USP, Bauru, SP; Doutora em Ciências Médicas pela Universidade Estadual de Campinas.

(3) Fonoaudióloga; Professora Doutora do Departamento de Fonoaudiologia da Faculdade de Odontologia de Bauru da Universidade de São Paulo, FOB-USP, Bauru, SP; Doutora em Educação Especial pela Universidade Federal de São Carlos.

Conflito de interesses: inexistente humana. A linguagem é caracterizada como o conhecimento de um código usado para representar ideias sobre o mundo. A criança aprende a linguagem à medida que a usa para produzir e compreender mensagens. Quando ocorrem dificuldades nos processos de aquisição e desenvolvimento da linguagem, podem ocorrer vários distúrbios e, entre eles, encontram-se os relacionados com a fluência, como a gagueira do desenvolvimento e a taquifemia ${ }^{1-3}$.

Outras desordens, categorizadas como distúrbios da fluência, como aquelas pertencentes aos quadros de gagueira adquirida (gagueira psicogênica e alterações decorrentes dos distúrbios motores da fala) não serão foco deste estudo, que se aterá, principalmente, à chamada gagueira de desenvolvimento $\mathrm{e}$, em segundo plano, à taquifemia. 
Fluência refere-se ao fluxo contínuo e suave da produção da fala. É um aspecto de produção de fala, relacionado à continuidade, velocidade e/ou esforço com os quais as unidades fonológicas, lexicais, morfológicas e/ou sintáticas são produzidas. A fala envolve componentes linguísticos (aspectos formais, segmentais) e paralinguísticos (aspectos prosódicos, suprasegmentais), processados por diferentes sistemas neurais, que convergem para um sistema comum de saída. Assim, a fala fluente requer que os componentes estejam integrados e em sincronia ${ }^{4,5}$.

Sendo assim, a fluência fornece, ao próprio falante e ao ouvinte, parâmetros sobre a efetividade da linguagem. A fala fluente contém as nuances apropriadas do significado, associadas ao ritmo, velocidade, entonação e às intenções comunicativas. $O$ falante fluente é aquele que pode produzir longas sequências de sílabas, sem esforço, combinando emissões contínuas. Dessa forma, a sua emissão torna-se o reflexo de sua habilidade e maturidade linguísticas ${ }^{2,5-7}$.

Com todas essas considerações sobre a fala fluente, a fala disfluente seria, então, aquela que apresenta quebras ou rupturas involuntárias em seu fluxo, suavidade, ritmo e/ou esforço com os quais as unidades fonológicas, lexicais, morfológicas e/ ou sintáticas da linguagem são faladas. Em consequência disso, os distúrbios da fluência seriam as alterações da fala, caracterizadas por essas rupturas e/ou esforço para falar ${ }^{4,5}$.

Fica claro, pelo exposto até aqui, que a definição dos distúrbios da fluência só pode ser dada em relação aos comportamentos que os compõem, ou seja, às disfluências. Estas são rupturas no fluxo da fala, que variam em maior ou menor grau, dependendo do dia, da emoção envolvida e do domínio sobre o tema da conversação ${ }^{4,6,8,9}$ e que podem ser classificadas como normais (não-gagas), anormais (gagas) ou ambíguas (algumas vezes computadas como normais e algumas vezes como anormais). Caracterizadas por repetições, prolongamentos e hesitações na fala, as disfluências são consideradas normais em crianças na fase de aquisição de linguagem ${ }^{4,10-14}$.

A gagueira é o mais comum e reconhecido dos distúrbios da fluência e suas principais manifestações são as disfluências, principalmente as chamadas disfluências gagas (bloqueios, repetições e prolongamentos de sons e sílabas). Considerada um distúrbio universal, referido em todas as partes do mundo e encontrado entre todas as raças e classes socioeconômicas, a gagueira afeta mais o sexo masculino que o feminino, numa proporção de $3: 1$, sendo que o risco é três vezes maior entre parentes de primeiro grau de indivíduos que gaguejam ${ }^{12,15,16}$.

Comportamentos secundários não-verbais, também chamados de comportamentos acessórios, podem integrar o quadro da gagueira, como os esforços para emitir o som das palavras, tensão muscular, movimentos corporais evidentes, piscar de olhos, protrusão de língua, entre outros 1,16,17. Estas dificuldades funcionais de comunicação geram impactos negativos na qualidade de vida do indivíduo que gagueja ${ }^{13}$.

Atualmente existem várias teorias que explicam a etiologia da gagueira, apesar de não haver ainda um consenso geral sobre esse assunto. Sabe-se apenas que existem traços predisponentes para o seu surgimento, como fatores hereditários, biológicos, psicológicos, linguísticos e sociais. Estudos genéticos ${ }^{5,18}$ mostram que a frequência da gagueira é consideravelmente maior entre parentes de primeiro grau e em pessoas do sexo masculino. Estes mesmos estudos identificaram diversas regiões cromossômicas que podem abrigar genes susceptíveis à gagueira; no entanto, apesar dessas constatações, não se pode afirmar que uma criança nasça gaga e mesmo que a hereditariedade a predisponha à gagueira, sendo a prevenção um fator importante a ser trabalhado com as chamadas populações de risco.

Dentre os distúrbios da fluência, pode-se citar a taquifemia, que se refere à alteração de fluência caracterizada por uma velocidade de fala rápida e/ ou irregular, disfluências excessivas e geralmente outros sintomas como erros de linguagem ou fonológicos e déficits de atenção. Também pode ocorrer de forma isolada como uma alteração da fluência ou pode coexistir com a gagueira, como frequentemente ocorre ${ }^{4}$. É considerada um problema de linguagem associado a uma disfunção no sistema nervoso central, sendo que o indivíduo não tem consciência do seu problema e não apresenta componentes emotivos envolvidos ${ }^{19,20}$.

Devido à variedade de definições advindas dos diferentes fatores etiológicos e da diversidade sintomatológica dos distúrbios da fluência ${ }^{6,12,15}$, torna-se evidente a importância de pesquisas para a caracterização desses transtornos, em amostras significativas de indivíduos. A possibilidade de encontrar um número expressivo de indivíduos com distúrbios da fluência, em uma clínica-escola de Fonoaudiologia, impulsionou e justificou este estudo, que pretende contribuir para a obtenção de uma identificação mais precisa do perfil dessa população.

Portanto, o objetivo desta pesquisa foi caracterizar a população de indivíduos com distúrbios de fluência, atendidos na Clínica de Distúrbios de Fluência do Curso de Fonoaudiologia da 
Universidade de São Paulo (USP - Campus Bauru), quanto à idade, gênero, queixa inicial, diagnóstico fonoaudiológico, antecedentes familiares, manifestações, gravidade, frequência das disfluências e possíveis alterações associadas, comparando tais dados com a literatura estudada.

\section{MÉTODOS}

Foram analisados 194 prontuários de indivíduos atendidos na Clínica de Distúrbios da Fluência do Curso de Fonoaudiologia da Universidade de São Paulo (USP - Campus Bauru), entre os anos de 1992 a 2005. Esse número de prontuários corresponde a todos os indivíduos que foram atendidos no período especificado pela referida clínica. Os critérios de seleção seguidos foram: o prontuário pertencer à Clínica de Distúrbios da Fluência (Estágio de Distúrbios da Fluência, por se tratar de uma clínica-escola), da clínica-escola do Curso de Fonoaudiologia da FOB-USP e conter a queixa em relação à fluência.

Como num período de 13 anos (entre 1992 e 2005) houve uma grande variabilidade dos protocolos adotados para avaliação das disfluências, foi elaborado, pela pesquisadora, um outro para anotação dos dados dos prontuários (protocolo de avaliação de prontuários), que contemplasse os objetivos da pesquisa. Continha questões referentes à idade na época do início dos sintomas e na época em que foi diagnosticada a gagueira, ano em que procurou atendimento, sexo do paciente, queixa inicial e diagnóstico fonoaudiológico fornecido pela clínica. Além dessas informações, foram anotados dados sobre a presença de histórico familiar positivo para a presença de alterações de fluência e/ou linguagem, tipologia, gravidade e frequência das manifestações da dislfuência e outras alterações associadas (qualidade vocal, coordenação pneumofonoarticulatória, velocidade de fala e/ou articulação, ritmo/ entonação, alterações miofuncionais orais e de funções reflexovegetativas). Alguns dados não foram encontrados em todos os prontuários e, portanto, na apresentação dos resultados tal fato será apontado na análise de cada categoria.

Por se tratar de uma clínica-escola, no início do atendimento, o indivíduo ou responsável assinava um termo de consentimento livre e esclarecido, autorizando a utilização dos dados do prontuário para finalidade científica. O acesso aos prontuários, para fins de realização desta pesquisa, foi autorizado pelos responsáveis pela referida clínica. Todos os procedimentos foram aprovados pelo Comitê de Ética em Pesquisa (CEP) da Faculdade de Odontologia de Bauru (FOB-USP), sob protocolo no 23/2006.
A análise de dados foi realizada de forma descritiva e quantitativa, por meio do cômputo de frequência das variáveis e cálculo de porcentagens, e apresentada em gráficos e tabelas, para que fosse possível confrontar os achados com os dados da literatura.

\section{RESULTADOS}

Os resultados são referentes aos 194 prontuários analisados, embora alguns dados tenham sido analisados separadamente, pelo fato de que nem todos os prontuários continham a totalidade das informações constantes no protocolo de análise proposto, sendo que, na apresentação de resultados que se segue, foi especificado, para cada categoria de resposta, o número total de prontuários analisados. Como já citado, alguns dados não foram encontrados em todos os prontuários e, portanto, na apresentação dos resultados tal fato será apontado na análise de cada categoria. Portanto, a ausência da totalidade das informações em algumas categorias foi decorrente da falta de dados contidos nos prontuários.

A idade dos indivíduos na época da procura pelo atendimento na clínica-escola, variou de dois a 56 anos, conforme Figura 1. A Figura 2 apresenta a idade dos indivíduos quando os primeiros sintomas da queixa surgiram, sendo que esse dado foi encontrado em 138 prontuários ( $71 \%$ da amostra).

Com relação ao gênero, dos 194 prontuários analisados, $72 \%$ (140 indivíduos) eram de indivíduos do sexo masculino e $28 \%$ (54 indivíduos) do feminino.

Entre as queixas iniciais, relatadas pelos informantes, a maioria $(68 \%$ - 132 indivíduos) relatou gagueira. Entretanto, outros 9\% (17 indivíduos) apresentaram, além desta, outras queixas associadas (alterações vocais, dificuldade na linguagem, fala e/ou na escrita). Em $5 \%$ dos prontuários (10 prontuários) não houve registro de queixa e em 15\% dos casos (29 prontuários) o informante disse que houve dificuldades para falar e outros 3\% (6 prontuários) apresentaram apenas queixa associada de voz. Os informantes foram os pais dos indivíduos (nos casos de crianças) ou o próprio indivíduo (no caso de adultos).

Apesar do diagnóstico fonoaudiológico ser obrigatório a todos os pacientes atendidos pela Clínica de Fonoaudiologia, apenas 94 prontuários (48\% da amostra) continham este diagnóstico de forma explícita (em laudo). Assim, em 100 prontuários (52\% da amostra) não foram encontrados registros do diagnóstico fonoaudiológico. A Tabela 1 mostra a distribuição dos prontuários analisados segundo 0 diagnóstico fonoaudiológico anotado em prontuário, sendo a maioria de gagueira. 
Em 57\% dos prontuários (110 indivíduos) foram encontrados dados positivos sobre o histórico familiar, ou seja, informações sobre a presença de alguma alteração na fala e/ou linguagem e/ou fluência em algum parente. A Figura 3 indica o grau de parentesco do paciente com os membros da família que possuíam problemas na fala e/ou linguagem e/ou fluência.
Foram encontradas em apenas 105 prontuários (54\% da amostra) anotações referentes às manifestações das disfluências, tendo sido citados 11 tipos (Figura 4). No restante dos prontuários (89 prontuários - 46\% da amostra) não foram encontrados registros referentes às manifestações e/ou tipologia das disfluências. Nos prontuários em que havia tais registros, as manifestações predominantes foram a

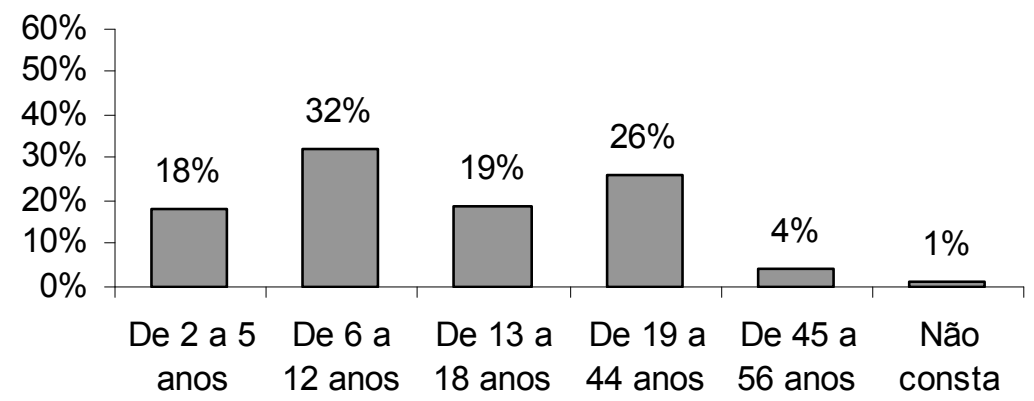

Figura 1 - Idade dos pacientes na época da procura pelo atendimento fonoaudiológico na clínicaescola $(\mathrm{N}=194)$

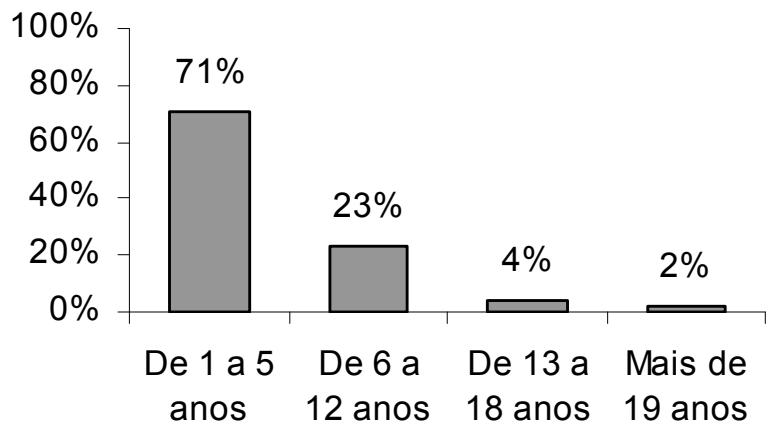

Figura 2 - Idade dos pacientes no ínicio dos primeiros sintomas associados à gagueira $(\mathrm{N}=138)$

Tabela 1 - Distribuição dos prontuários analisados segundo o diagnóstico fonoaudiológico (N=94)

\begin{tabular}{lcc}
\hline Diagnóstico & Número de pacientes & $\%$ \\
\hline Gagueira & 63 & 68 \\
Grupo de risco para gagueira & 4 & 4 \\
Taquifemia & 7 & 7 \\
Afasia & 1 & 1 \\
Disfluência normal de fala e disfonia associada & 1 & 1 \\
Gagueira e disfonia associada & 1 & 1 \\
Disfluência normal da fala & 9 & 10 \\
Gagueira, alterações vocais e de escrita associadas & 1 & 1 \\
Dispraxia global & 1 & 1 \\
Distúrbio de linguagem & 1 & 1 \\
Gagueira e alteração de leitura e/ou escrita associada & 2 & 2 \\
Gagueira e alteração de motricidade orofacial associada & 3 & 3 \\
\hline Total & 94 & 100
\end{tabular}


Duarte TF, Crenitte PAP, Lopes-Herrera SA

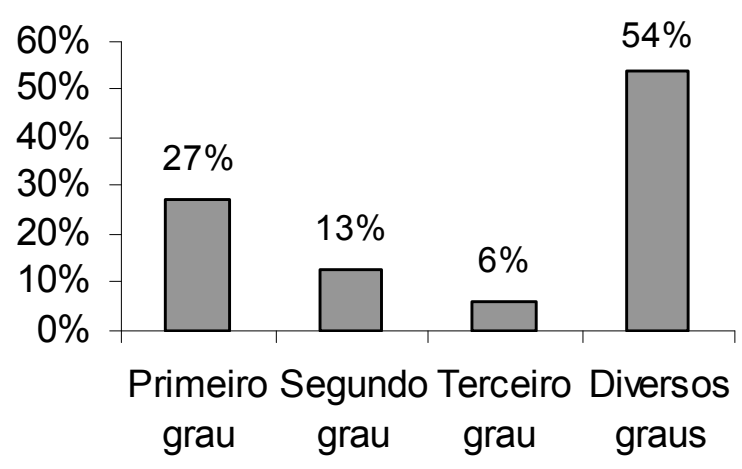

Figura 3 - Grau de parentesco do paciente com os membros da família que possuíam problemas na fala e/ou linguagem e/ou fluência $(N=110)$

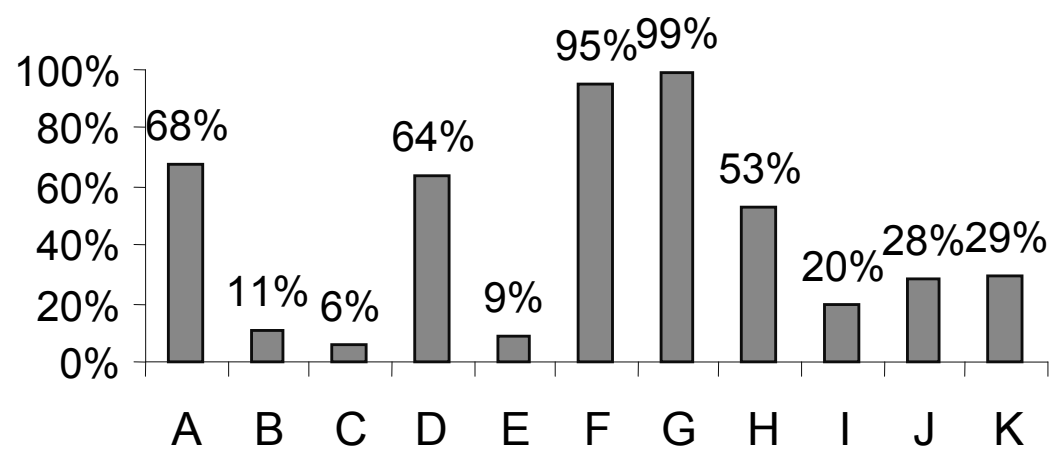

Legenda: A - Prolongamentos; B - Pausas; C - Palavras não terminadas; D - Hesitações; E - Revisões; F - Bloqueios; G - Repetições de sílabas; H - Repetições de palavras; I - Repetições de frases; J - Repetições de sons; K - Interjeições.

Figura 4 - Manifestações das disfluências apresentadas pelos pacientes e anotadas em prontuário $(\mathrm{N}=105)$

repetição de sílabas e os bloqueios, acompanhados dos prolongamentos e hesitações. Os movimentos associados foram relatados em 58 prontuários (30\% da amostra), conforme mostra a Tabela 2, sendo mais frequentes os movimentos associados de olhos, membros superiores, membros inferiores, cabeça e face.

$\mathrm{Na}$ análise de prontuários realizada, foram coletados dados referentes à gravidade e frequência das disfluências, nos casos diagnosticados como gagueira, ao início e ao final do tratamento, sendo que apenas 35 prontuários (18\%) continham dados referentes à gravidade da gagueira no início do tratamento e $12(6 \%)$ continham dados sobre a gravidade ao final (Figura 5). Dados referentes à frequência da gagueira ao início do tratamento foram encontrados em 15 prontuários (8\%) e, ao final do tratamento, em 12 (6\%), como mostra a Figura 6. Não foram encontrados dados relativos à gravidade e frequência das disfluências na maioria das amostras (aproximadamente $82 \%$ ), porque tais informa- ções não estavam anotadas nos prontuários, nem no início e nem ao final do tratamento.

Quando o diagnóstico de gagueira estava explicitado no prontuário, verificou-se a presença das seguintes alterações associadas à gagueira, incluídas no diagnóstico: tensões, alterações na qualidade vocal e na coordenação pneumofonoarticulatória, além de alterações na motricidade orofacial. Os dados sobre as tensões associadas aos momentos de disfluência nos indivíduos gagos foram encontrados em 60 prontuários $(31 \%$ da amostra), sendo que, destes, $58 \%$ (34 indivíduos) apresentaram tensão cervical, 24\% (14 indivíduos), tensão facial e cervical, $16 \%$ (10 indivíduos), tensão facial e apenas $2 \%$ (2 indivíduos) apresentaram tensão generalizada.

Dados sobre a qualidade vocal estiveram presentes em 69 prontuários (35\% da amostra) e, desses, 48\% (34 indivíduos) apresentaram alterações. No restante dos prontuários (125 prontuários - 65\% da amostra) não havia anotações sobre a qualidade vocal dos indivíduos. Nos prontuários 
Tabela 2 - Movimentos associados à disfluência encontrados nos prontuários analisados ( $\mathrm{N}=57$ )

\begin{tabular}{lcc}
\hline Movimentos Associados & Número de pacientes & $\%$ \\
\hline Cabeça & 2 & 3 \\
Olhos & 15 & 26 \\
Nariz & 3 & 5 \\
Língua & 3 & 5 \\
Lábios e olhos & 2 & 3 \\
Membros superiores & 6 & 11 \\
Membros inferiores & 6 & 11 \\
Cabeça e face & 6 & 11 \\
Cabeça, face e membros superiores & 6 & 11 \\
Cabeça, face e membros inferiores & 4 & 7 \\
Membros inferiores e superiores & 3 & 5 \\
Cabeça, face, membros superiores e inferiores & 1 & 2 \\
\hline Total & 57 & 100 \\
\hline
\end{tabular}

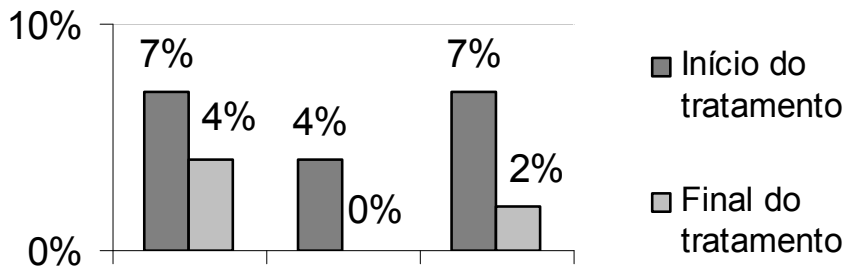

Leve Moderada Severa

Figura 5 - Grau de severidade da gagueira apresentado pelos pacientes ao início $(\mathrm{N}=35)$ e ao final do tratamento $(\mathrm{N}=12)$

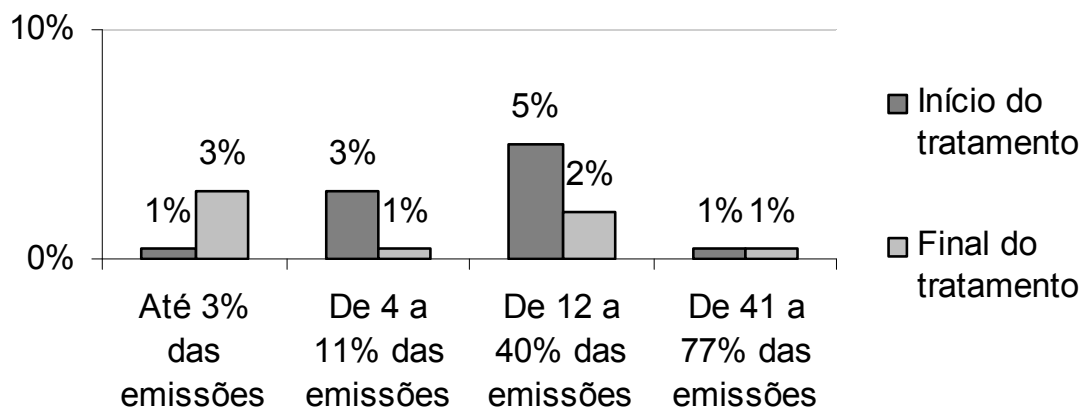

Figura 6 - Frequência da gagueira apresentada pelos pacientes ao início $(\mathrm{N}=15)$ e ao final do tratamento $(\mathrm{N}=12)$

que continham informações sobre alterações da qualidade vocal, $9 \%$ (7 prontuários) correspondiam a alterações na intensidade vocal, $9 \%$ (7 prontuários) a alterações no sistema de ressonância e 30\% (21 prontuários) a alterações orgânicas nas pregas vocais. Já os dados sobre coordenação pneumofonoarticulatória (CPFA) foram encontrados em 114 prontuários (59\% da amostra), estando a CPFA alterada em $74 \%$ dos casos (84 prontuários). Essas alterações eram relativas ao uso de ar de reserva, pausas inadequadas e tempo máximo de fonação alterado.

Informações sobre motricidade orofacial foram encontradas em 87 prontuários (45\% da amostra), sendo que no restante dos prontuários (107 deles, constituindo $55 \%$ da amostra) não havia informações sobre motricidade orofacial. Nos prontuários em que constavam tais informações, verificou-se a 
presença de alteração de tonicidade ( $41 \%$ da amostra, perfazendo um total de 36 indivíduos), funções reflexo-vegetativas (16\% - 14 indivíduos), mobilidade (14\% - 12 indivíduos), morfologia (11\% - 10 indivíduos), tonicidade e funções reflexovegetativas em associação ( $6 \%$ - 5 indivíduos) e tonicidade e mobilidade associadas ( $11 \%$ - 10 indivíduos).

Entre as outras alterações associadas, dados sobre a manutenção de contato visual constavam em 56 prontuários ( $23 \%$ da amostra). O comportamento de evitar contato visual no momento das disfluências foi encontrado em $9 \%$ dos casos (17 prontuários), enquanto que outros 20\% (39 prontuários) não apresentaram referências de alterações nesse quesito e os demais 138 prontuários (71\% restantes) não continham dados referentes a esse item.

Alterações de velocidade da fala foram relatadas em 128 prontuários (66\% da amostra), sendo que nos demais prontuários ( 66 deles, constituindo $28 \%$ da amostra) não havia anotações sobre essa característica. Dos 128 prontuários onde se encontravam anotações sobre a velocidade de fala, em $35 \%$ (45 prontuários) não havia explicações sobre as alterações, em $53 \%$ dos casos (68 indivíduos) a velocidade de fala estava aumentada e em 24\% (31 indivíduos), estava diminuída. Ao analisar os dados referentes a tais alterações de velocidade de fala, observou-se que houve, nos casos de velocidade de fala alterada, associação de alterações de articulação em 38\% (49 indivíduos), que também apresentavam alterações de articulação, relacionadas à imprecisão articulatória ( $20 \%$ - 10 indivíduos), articulação travada (16\% - 8 indivíduos) e alterações não especificadas (64\% - 31 indivíduos).

De um total de 94 prontuários, onde constavam anotações sobre ritmo e entonação da fala, $14 \%$ dos indivíduos (13 prontuários) apresentaram alterações e $86 \%$ dos indivíduos atendidos não apresentaram (81 prontuários). No restante dos prontuários (110 prontuários - $48 \%$ da amostra), não havia anotações referentes ao ritmo e entonação de fala.

No estudo aqui apresentado, dos prontuários analisados, 31\% (60 indivíduos) apresentaram relatos de atraso de linguagem. Já em $58 \%$ dos prontuários (113) não foram encontrados dados referentes à aquisição e desenvolvimento de linguagem e 11\% (21 indivíduos) apresentaram relatos de desenvolvimento normal da linguagem.

\section{DISCUSSÃO}

O protocolo de avaliação, utilizado para realizar a coleta de dados dos prontuários, foi eficiente para tal, mostrando apenas algumas dificuldades em razão das mudanças e evoluções ocorridas ao longo dos anos, no que diz respeito ao processo de avaliação das disfluências (análise da gravidade, terminologia, entre outros) e à falta de informações contidas nos prontuários. Analisando os prontuários observou-se que nem todos (194 prontuários que faziam parte da amostra) continham as informações necessárias para a análise completa e preenchimento do protocolo proposto, o que demonstra que tais anotações devem ser feitas com mais rigor e critério. Em termos de prestação de serviços na área de saúde, a questão da documentação dos atendimentos é de fundamental importância.

Dos 94 prontuários em que havia a anotação explícita do diagnóstico fonoaudiológico relacionado à presença de distúrbios da fluência, a maioria (63 prontuários $-68 \%$ da amostra) era de gagueira e apenas $4 \%$ eram de taquifemia, o que justifica que as discussões a seguir abarquem prioritariamente tais casos.

Dos resultados encontrados na análise dos prontuários, estão de acordo com os dados encontrados na literatura estudada $5,6,8,16,18$ as seguintes características: maior proporção do sexo masculino entre indivíduos afetados, maior frequência de gagueira em parentes de primeiro grau e presença de alterações associadas, na maioria dos casos diagnosticados como gagueira.

Com relação à análise da variável idade, foram encontrados prontuários de indivíduos de 2 a 56 anos. É importante esclarecer que aos dois anos de idade não é possível diagnosticar a gagueira. Porém, o aparecimento do sintoma, nessa época, é fator de risco para o desenvolvimento de gagueira, sendo necessária a intervenção fonoaudiológica para a prevenção. Segundo a classificação proposta pela literatura ${ }^{8,15-17}, 94 \%$ dos indivíduos apresentou gagueira desenvolvimental, 4\%, gagueira intermediária e apenas $2 \%$, gagueira crônica. A gagueira desenvolvimental tende a desaparecer por volta dos sete anos. Nesses casos, é importante o trabaIho de prevenção e intervenção precoce, logo após o aparecimento dos primeiros sintomas ${ }^{9}$.

Comparando a idade dos indivíduos na época de aparecimento dos primeiros sintomas e a idade na época do diagnóstico (e suposta procura pelo atendimento), observa-se uma discrepância de valores. Tal discrepância pode resultar em prejuízo no processo terapêutico, devido à demora para a procura de atendimento fonoaudiológico. Embora $71 \%$ dos indivíduos (138 indivíduos) tenham apresentado os primeiros sintomas entre 1 e 5 anos, apenas 32\% (62 indivíduos) procuraram atendimento entre $6 \mathrm{e}$ 12 anos e $30 \%$ (58 indivíduos) somente procuraram atendimento na fase adulta.

Em relação às queixas, embora a maioria tenha se referido à gagueira, outras queixas foram infor- 
madas. Isto pode ser resultado do desconhecimento do informante sobre o que é a gagueira, sobre a existência de outros distúrbios da fluência, ou sobre o quanto as alterações de fala, linguagem e voz podem chamar a atenção, sobrepondo-se, muitas vezes, à queixa relacionada à fluência.

Segundo os diferentes estudos analisados e as diversas definições fornecidas por cada autor ${ }^{4,6,7,15-17}$, a gagueira pode apresentar as seguintes manifestações (tipologia das disfluências): alterações na entonação, velocidade, ritmo, pausas inadequadas, interrupções temporais, repetições, prolongamentos, bloqueios, hesitações, interjeições, tensões e reações emocionais. Dessas manifestações, ficou clara, neste estudo, a presença predominante das seguintes disfluências: repetição de sílabas (99\% 105 indivíduos), bloqueios (95\% - 100 indivíduos), bloqueiosacompanhados de prolongamentos(68\%71 indivíduos) e hesitações (64\% - 67 indivíduos), dados esses compatíveis com estudos encontrados na literatura ${ }^{4,10-12}$. De forma geral, a tipologia das manifestações apresentadas não variam ao longo da vida, ou seja, o padrão de rupturas de fala não sofre grande variabilidade, podendo indicar que a maturação do sistema neurolinguístico para a fluência se estabelece funcionalmente já nos primeiros anos de vida e se mantém ao longo da vida ${ }^{14}$.

Um fator importante, citado na literatura $7,8,17$, é a evitação do contato visual por indivíduos gagos, durante os momentos de disfluência. Por haver poucos prontuários com tal informação, a análise ficou comprometida, apesar de se verificar a presença desse comportamento referida em $9 \%$ dos casos (17 prontuários).

Na maioria dos prontuários (53\%) em que constavam informações sobre velocidade de fala (128 prontuários), esta se apresentava aumentada, assim como associada à queixas sobre o ritmo, o que pode estar associado ao diagnóstico de taquifemia ${ }^{3,4,7}$. Também foram encontradas na amostra analisada, alterações de velocidade de fala associadas a alterações na articulação ( $38 \%-49$ casos) e alterações de ritmo associadas a alterações na entonação ( $14 \%$ - 13 casos). A literatura ${ }^{20}$ confirma a presença de um pobre controle temporal para a coordenção dos processos motores em indivíduos disfluentes, influenciando na articulacao e velocidade de fala.

Observou-se que não há muitos relatos, na literatura, relacionados a histórico positivo para a presença de atraso de fala e linguagem, em indivíduos com distúrbios da fluência. Neste estudo foram encontrados dados relevantes sobre tal característica, evidenciados pelo histórico positivo para a presença de atraso de fala e linguagem em 31\% dos prontuários dos indivíduos gagos avaliados (60 prontuários). Apenas uma pesquisa com indivíduos gagos ${ }^{3}$ mostrou que $26,5 \%$ dos indivíduos apresentava atraso de fala e linguagem. Os valores encontrados neste estudo são compatíveis com os valores dessa pesquisa.

\section{CONCLUSÃO}

Com base nos dados coletados dos prontuários analisados, é possível concluir que o perfil da população estudada encontra-se compatível com as características relatadas pela literatura para indivíduos com distúrbios da fluência, sendo estas referentes ao surgimento dos primeiros sintomas entre 1 e 5 anos, maior acometimento do gênero masculino, histórico familiar e de atraso de fala e linguagem positivo na maioria dos casos, manifestações predominantes de repetição de sílabas, bloqueios, bloqueios acompanhados de prolongamentos e hesitações.

O número expressivo de prontuários analisados permite que os resultados obtidos sejam significativos, sendo que, na literatura pesquisada, não se encontraram estudos com um grande número de participantes. Pesquisas similares podem ser desenvolvidas a partir do estudo aqui apresentado, de forma a ampliar o conhecimento existente na área dos distúrbios da fluência, o que irá contribuir não só para o diagnóstico, mas também para o desenvolvimento mais eficaz de intervenções fonoaudiológicas e programas de atuação, direcionados a essa população.

\section{AGRADECIMENTOS}

Agradecemos à Universidade de São Paulo (USP), à Faculdade de Odontologia de Bauru (FOBUSP) e à Clínica-Escola do Curso de Fonoaudiologia da FOB-USP pela oportunidade concedida para a realização desta pesquisa. Agradecemos também ao Conselho Nacional de Desenvolvimento Científico e Tecnológico (CNPq) por financiar este trabalho, criando condições para o cumprimento do mesmo. 


\begin{abstract}
Purpose: to characterize the population of subjects with fluency disorders as for age, gender, initial complaint, speech therapy diagnosis, family history, manifestations, degree of severity and frequency of disfluency and possible associated alterations, comparing the data to literature. Methods: analysis of 194 medical records of individuals with fluency disorders at the Speech Language Pathology and Audiology Clinic at USP (Bauru Campus), through a protocol containing questions related to the items proposed in the objective. Results: from the 194 medical records, 140 were male $(72 \%$ of the sample) and 54 (28\%) female; among the reported complaints, 68\% (132 medical records) were about stuttering, $23 \%(n=45)$ regarding other fluency disorders (tachyphemia, motor speech disorders, etc) and others $9 \%(n=17)$ had associated complaints (vocal alterations, oral and/or written language and speech). With regard to family history, $57 \%(n=110)$ had more than one relative in their family with speech and/or language alterations. The manifestations of disfluency cited in $54 \%$ of the medical records $(n=105)$ from subjects diagnosed with stuttering were blocks, repetitions and prolongations. A history of language retardation was ascertained in cases of stuttering in $31 \%$ of the cases (60 medical records), which, together with the other symptoms described in literature, should be taken into consideration when carrying out an early diagnosis. Conclusion: based on the found data, we concluded that the studied population is characterized for showing the following: the beginning of the first symptoms between 1 and 5-year old, greater involvement of males, a positive family history and late speech and language; , disfluency manifestation found were repetition of syllables, block, block accompanied by extensions and hesitations.
\end{abstract}

KEYWORDS: Communication; Stuttering; Language; Signs and Symptoms

\section{REFERÊNCIAS}

1. Resolução do Conselho Federal de Fonoaudiologia oㅜ 305. março/2004. Disponível em: URL: http://www.fonoaudiologia.org.br/servlet/ ConsultaLegislacao acao $=$ V\&leild $=46$

2. Bohnen AJ. Sobre paradigmas, linguagem e gagueira. Rev Fono Atual. 2000; 14:8-13.

3. Bloodstein $\mathrm{O}$. Some empirical observations about early stuttering: a possible link to language development. J Commun Disord. 2006; 39(3): 185-91.

4. Sassi FC, Campanatti-Ostiz $\mathrm{H}$, Andrade CRF. Terminologia: fluência e desordens da fluência. Pró-Fono. 2001; 13(1):107-13.

5. Andrade CRF, Schochat E. Comparação entre os achados neurolinguísticos e neuroaudiológicos nas gagueiras. Pró-Fono. 1999; 11(2):27-30.

6. Moraes RA, Nemr K. A gagueira sob diferentes olhares: análise comparativa das abordagens de quatro autoras. Rev CEFAC. 2007; 9(3):300-18. dx.doi.org/10.1590/S1516-18462007000300004

7. Schiefer AM. Abordagem psicolinguística da fluência. In: Ferreira LP, Befi-Lopes DM, Limongi SCO, organizadoras. Tratado de fonoaudiologia. São Paulo: Roca; 2004. p. 1035-9.

8. Bohnen AJ. Avaliando crianças com gagueira. In: Ribeiro IM, organizador. Conhecimentos essenciais para atender bem a pessoa com queixa de gagueira. São José dos Campos: Pulso; 2005. p.73-8.

9. Merçon SMA, Nemr K. Gagueira e disfluência comum na infância: análise das manifestações clínicas nos seus aspectos qualitativos e quantitativos. Rev CEFAC. 2007; 9(2):174-9. dx.doi. org/10.1590/S1516-18462007000200005

10. Juste F, Andrade CRF. Tipologia das rupturas de fala e classes gramaticais em crianças gagas $e$ fluentes. Pró-Fono. 2006; 18(2):129-40.

11. Colacicco FB, Schiefer AM, Osborn E. Medidas acústicas de duração da fala de indivíduos gagos e não gagos. Rev Fono Atual. 2005; 8(31):26-30.

12. Colacicco FB, Arcuri CF, Osborn E, Schiefer AM. Caracterização dos aspectos de duração da fala de indivíduos fluentes e gagos. Rev Soc Bras Fonoaudiol. 2006; 11(3):158-62.

13. Andrade CRF, Sassi FC, Juste FS, Ercolin B. Qualidade de vida em indivíduos com gagueira desenvolvimental persistente. Pró-Fono. 2008; 20(4):219-24.

14. Martins VO, Andrade CRF. Perfil evolutivo da fluência da fala de falantes do Português brasileiro. Pró-Fono. 2008; 20(1):7-12.

15. Barbosa LMG. O sentido psicológico da fala: um enfoque psicossocial da gagueira. Rev Fono Atual. 1999; 3(7):8-10. 
16. Andrade CRF. Gagueira infantil. In: Marconde E, organizador. Fonoaudiologia em pediatria. São Paulo: Sarvier; 2003. p. 61-3.

17. Barbosa LMG. Noções básicas sobre a gagueira: suas características, sua etiologia e as teorias sobre sua natureza. In: Ribeiro IM, organizador. Conhecimentos essenciais para atender bem a pessoa com queixa de gagueira. São José dos Campos: Pulso; 2005. 84p.

18. Wittke-Thompson JK, Ambrose N, Yairi E, Roe C, Cook EH, Ober C, et al. Genetic studies of stuttering in a founder population. J Fluency Disord. 2007; 32(1):33-50.

19. Degiovani VM. Diagnóstico diferencial das disfluências. In: Ribeiro IM, organizador. Conhecimentos essenciais para atender bem a pessoa com queixa de gagueira. São José dos Campos: Pulso; 2005. p.33-41.

20. Andrade CRF, Sassi FC, Juste FS, Meira MIM. Atividades de fala e não-fala em gagueira: estudo preliminar. Pró-Fono. 2008; 20(1):67-70.

DOI: 10.1590/S1516-18462009005000027

RECEBIDO EM: 21/12/2007

ACEITO EM: 13/01/2009

Endereço para correspondência:

Simone Aparecida Lopes-Herrera

Alameda Dr. Octávio Pinheiro Brizola, 9-75

Bauru - SP

CEP: 17012-901

E-mail: lopesimone@usp.br 